\title{
Gene expression changes associated with aging in C. elegans*
}

\author{
Tamara R. Golden ${ }^{\S}$, Simon Melov`, Buck Institute for Age Research, \\ Novato, CA 94945 USA
}

\section{Table of Contents}

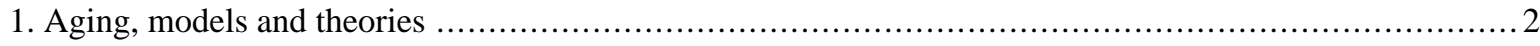

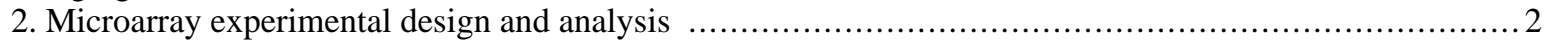

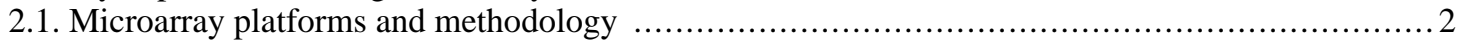

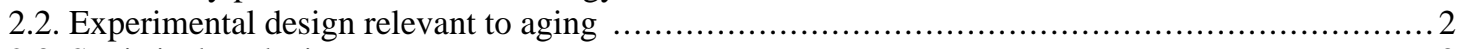

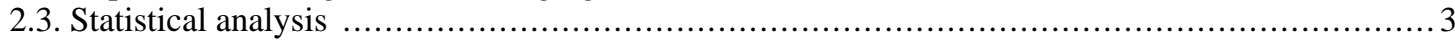

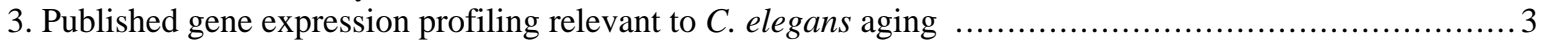

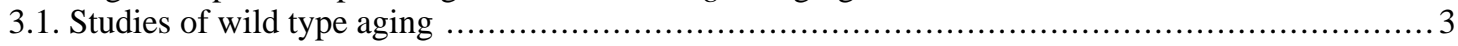

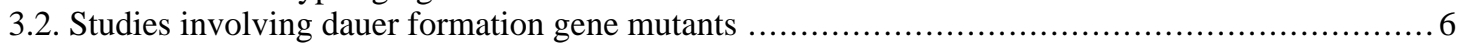

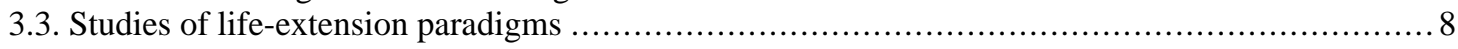

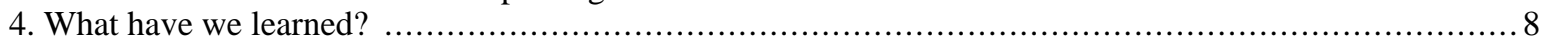

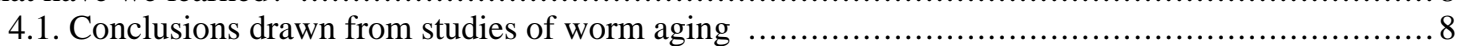

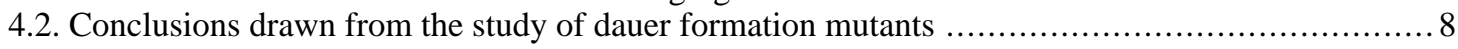

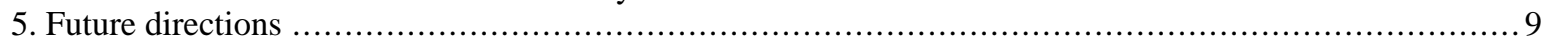

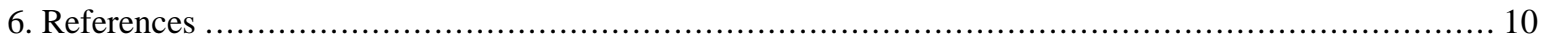

\begin{abstract}
Great inroads into the understanding of aging have been made using $C$. elegans as a model system. Several genes have been identified that, when mutated, can extend lifespan. Yet, much about aging remains a mystery, and new technologies that allow the simultaneous assay of expression levels of thousands of genes have been applied to the question of how and why aging might occur. With correct experimental design and statistical analysis, differential gene expression between two or more populations can be obtained with high confidence. The ability to survey the entire genome in an unbiased way is a great asset for the study of complex biological phenomena such as aging. Aging undoubtedly involves changes in multiple genes involved in multiple processes, some of which may not yet be known. Gene expression profiling of wild type aging, and of strains with increased life spans, has provided some insight into potential mechanisms, and more can be expected in the future.
\end{abstract}

\footnotetext{
*Edited by Monica Driscoll and Garth Patterson. Last revised January 23, 2007. Published in this revised form February 12, 2007. This chapter should be cited as: Golden, T.R. and Melov, S. Gene expression changes associated with aging in C. elegans (February 12, 2007), WormBook, ed. The C. elegans Research Community, WormBook, doi/10.1895/wormbook.1.127.2, http://www.wormbook.org.

Copyright: (C) 2007 Tamara R. Golden and Simon Melov. This is an open-access article distributed under the terms of the Creative Commons Attribution License, which permits unrestricted use, distribution, and reproduction in any medium, provided the original author and source are credited.

${ }^{\S}$ To whom correspondence should be addressed. E-mail: tgolden@buckinstitute.org or smelov@buckinstitute.org
} 


\section{Aging, models and theories}

Aging, or organismal senescence, is defined as gradual changes in an organism that "adversely affect its vitality and function, but most importantly, increase the mortality rate as a function of time" (Finch, 1990). The etiology of the aging process can be viewed within the framework of evolutionary theory; natural selection cannot act on post-reproductive animals, hence there is no selection for mechanisms to maintain an organism past reproductive age. Aging can therefore be regarded as a byproduct of this lack of maintenance. Numerous theories exist to explain the aging phenotype within this evolutionary context, two of the most influential being those of the "disposable soma" (Kirkwood, 1977; Kirkwood and Holliday, 1979) and of antagonistic pleiotropy (Williams, 1957). The disposable soma theory posits that the organism must allocate resources between maintenance of somatic tissues and reproduction, resulting in a trade-off between reproductive fitness and life span. The theory of antagonistic pleiotropy proposes that genes that are actively selected because they increase reproductive fitness may have detrimental effects later in life and contribute to aging.

Consistent with these theories, various types of damage have been proposed to accumulate with age, either due to an increased rate of production, or because of decreased repair or clearance, of damage with time. Though oxidative damage (Beckman and Ames, 1998) and damaged DNA have become favored candidates to "cause" aging, it remains unknown what the most important source and targets of damage are, or if there is a common rate limiting step for aging in a given organism or tissue.

C. elegans is a powerful model system for the study of aging, because of its genetics, relatively short life span, and ease of propagation of populations of synchronized individuals. Numerous single-gene mutations (AGE genes) have been identified that increase $C$. elegans life span (summarized in the Genes and Interventions Database; http://sageke.sciencemag.org; Friedman and Johnson, 1988; Johnson, 2002; Kenyon et al., 1993; Kimura et al., 1997). The best characterized of these (daf-2, age-1) are in an insulin-like signaling pathway which culminates in altering the activity of the transcription factor daf-16 (Lin et al., 2001; Ogg et al., 1997). This same signaling pathway controls the entry of developing nematodes into the alternate, dauer larval stage (Riddle et al., 1981). The cost to fitness of these longevity mutants predicted by evolutionary theory was observed under stressful laboratory conditions (Walker et al., 2000).

Predictions for changes in gene expression with age can be made, based on the existing theories of aging. For example, a generalized increase in dysregulation of gene expression with age might be expected according to the mutation accumulation theory; such an increase in disorder was observed in a survey of age-related microarray studies in mammalian systems (Somel et al., 2006), and an age-related increase in heterogeneity in gene expression between individual cardiomyocytes has also been described in mouse (Bahar et al., 2006). Alternatively, one might expect to find systematic age-related changes in the expression of genes reflecting a need for increased repair in response to increased fragility, or reflecting degeneration of certain tissues or systems. Gene expression profiling experiments can, in an unbiased way, provide insight into the aging process.

\section{Microarray experimental design and analysis}

\subsection{Microarray platforms and methodology}

Microarray methodology is currently well established, with a number of platforms giving equivalent results, especially for highly-expressed genes (Barnes et al., 2005; Bowtell and Sambrook, 2003). Arrays using oligos as probes, including Affymetrix and Illumina technologies, may be less subject to cross-hybridization than cDNA arrays, if oligos are chosen appropriately. Alternatively, genome-wide gene expression profiling can be carried out using non-array approaches such as Serial Analysis of Gene Expression (SAGE) (Velculescu et al., 1995). A discussion of the various microarray platforms and specific issues involved with the preparation of C. elegans RNA are beyond the scope of this chapter, but are addressed elsewhere in the WormBook (see DNA microarrays). As the choice of platform to carry out microarray experiments has become more robust over the last several years, more emphasis tends to be placed on experimental design, and statistical analysis (Yang and Speed, 2002). This is particularly important when carrying out time-course experiments that are necessary in aging studies.

\subsection{Experimental design relevant to aging}

To enable the identification of age-related trends, any study of the aging process should examine at least three ages (young, middle-aged, old) and ideally many more than this. Choosing only two ages (young vs. old, for 
example), risks missing trends that may occur during the lifespan; a peak in mid-life followed by a decline to near youthful levels, for example, would be missed by an experimental design including only two ages.

Several steps can be taken to increase the reliability of the microarray data. Replicate arrays per sample can control for technical variance, but the number of replicates needed will depend upon the platform used and the magnitude of differential gene expression expected. Biological replicates are important to confirm that the population or individual studied at each age is representative. Randomization in sample and array processing is absolutely essential: day-to-day variation could conceivably mask true expression differences, or result in the identification of false positives if, for example, all "young" RNA samples or arrays are processed on one day and all "old" samples on another.

Beyond these basic principles, optimal experimental design depends on the questions to be asked, and should be considered after consultation with a statistician familiar with microarrays and high-dimensionality data analysis.

\subsection{Statistical analysis}

The analysis of microarray data is a constantly evolving field; with ever more sophisticated methods becoming available. Arguably, only in the last few years, have truly robust analytical methods been developed and employed for microarray data. Optimally, the researcher will have access to statistical expertise to aid in the interpretation of data. In lieu of working with a statistician, a researcher may choose from numerous software packages available either for purchase or in the public domain that can be used for analysis. Analysis of microarray data can move beyond simple pair-wise comparisons (young versus old for example) to include pattern-matching and looking for time-related trends. Powerful resources such as Bioconductor, an open source software project, can aid in these more complex approaches. Because microarray experiments generally involve thousands of comparisons, multiple testing must be taken into account when determining statistical significance. However one arrives at the list of differentially expressed genes, expression changes can be validated via Northern blotting, or quantitative PCR. Such validation techniques have become less routinely employed as the veracity of the microarray methodology has become more widely accepted.

Beyond the identification of differentially expressed genes, various software tools exist to help the researcher put their gene lists into a biological context. Gene ontology resources (Gene Ontology, DAVID, EASE) can indicate whether a specific biological function or compartment is over- or under-represented in a list of differentially expressed genes. Pathway analysis software can also help identify unifying themes in a list of differentially expressed genes (PathwayArchitect and GeneSpring). Such tools allow the researcher to move beyond lists of genes to the identification of biologically relevant processes with a level of statistical confidence.

\section{Published gene expression profiling relevant to $C$. elegans aging}

\subsection{Studies of wild type aging}

To date, three studies have focused exclusively on gene expression changes in wild type nematodes with age, but only one microarray study has compiled gene expression profiles at the whole-genome level over the range of the wild-type $C$. elegans lifespan (Lund et al., 2002). Another study examined four ages of wild-type nematodes over a subset of stress-related genes (Golden and Melov, 2004), while a third compared whole-genome expression profiles between young and old nematodes (Hill et al., 2000). These studies, and those discussed subsequently in this chapter, are summarized in the accompanying Table.

Before the appearance of microarray technology, other approaches were taken to identify age-related changes in gene expression in C. elegans. Fabian and Johnson (Fabian and Johnson, 1995) identified 12 transcripts that changed in abundance with age in $C$. elegans by generating a cDNA library from aged worms, and probing this library with poly $\left(\mathrm{A}^{+}\right) \mathrm{RNA}$ isolated from four or 14-day-old nematodes. Through sequencing of the clones, three of the nine transcripts that declined in abundance with age were determined to be vitellogenin genes, and one of the two transcripts that increased in abundance with age was an EF-1 $\alpha$ homologue. These authors also examined changes in RNA populations with age in wild-type and long-lived nematodes (Fabian and Johnson, 1995), finding that rRNA levels did not change, while poly-A $\left({ }^{+}\right)$RNA levels decreased with age in the long-lived and one wild-type strain. 
Table 1. Studies employing gene expression profiling to examine worm aging. Summary of the experimental design, statistical analysis, and results of each of the studies discussed in the chapter.

\begin{tabular}{|c|c|c|c|c|c|c|}
\hline Study & \begin{tabular}{|l} 
Experimental \\
Design
\end{tabular} & \begin{tabular}{|l} 
Platform \\
(number of \\
genes)
\end{tabular} & \begin{tabular}{|l} 
Number \\
of arrays
\end{tabular} & $\begin{array}{c}\text { Statistical } \\
\text { analysis }\end{array}$ & \begin{tabular}{|c|} 
Differentially \\
expressed genes
\end{tabular} & $\begin{array}{l}\text { Interesting genes } \\
\text { or gene families }\end{array}$ \\
\hline $\begin{array}{l}\text { Hill et al., } \\
2000\end{array}$ & $\begin{array}{l}8 \text { ages, } 2 \text { of which } \\
\text { were adult, pools } \\
\text { used, single array per } \\
\text { age. }\end{array}$ & $\begin{array}{l}\text { Affymetrix } \\
\text { (18791) }\end{array}$ & 8 & ANOVA & 4221 & $\begin{array}{l}\text { Metabolic-related, } \\
\text { muscle-related fall } \\
\text { between } 60 \text { hours } \\
\text { and } 2 \text { weeks }\end{array}$ \\
\hline $\begin{array}{l}\text { Lund et al., } \\
2001\end{array}$ & $\begin{array}{l}6 \text { adult ages, pools } \\
\text { used, three sterile } \\
\text { mutant strains, 3-6 } \\
\text { biological replicates } \\
\text { per age group. }\end{array}$ & \begin{tabular}{|l} 
cDNA \\
$(17871)$
\end{tabular} & 26 & ANOVA & 164 & $\begin{array}{l}\text { ins-2, ins-7, heat } \\
\text { shock proteins, } \\
\text { Tc3, "Mount 15" }\end{array}$ \\
\hline $\begin{array}{l}\text { Murphy et al., } \\
2003\end{array}$ & $\begin{array}{l}\text { Young adult } d a f-2 \text { or } \\
\text { age- } 1 \text { vs. control, } \\
\text { N2, or } d a f-2 ; d a f-16 \text {, } \\
1-4 \text { replicates per } \\
\text { comparison. Pools } \\
\text { used. Time course of } \\
\text { sterile mutant strain } \\
\text { treated with } d a f-2 \text {, or } \\
\text { daf- } 2+d a f-16 \text { RNAi, } \\
\text { or control vector, } \\
\text { one array per } \\
\text { condition per time } \\
\text { point. }\end{array}$ & $\begin{array}{l}\text { cDNA } \\
(18455)\end{array}$ & 60 & \begin{tabular}{|c|} 
SAM, \\
arbitrary \\
4-fold \\
cut-off, \\
hierarchical \\
clustering \\
\end{tabular} & 170 (SAM) & $\begin{array}{l}\text { ins-7, stress } \\
\text { response } \\
\text { (including sod-3, } \\
\text { heat shock } \\
\text { proteins), } \\
\text { anti-microbial } \\
\text { defense, } \\
\text { metabolism, } \\
\text { proteases }\end{array}$ \\
\hline $\begin{array}{l}\text { McElwee et } \\
\text { al., } 2003\end{array}$ & $\begin{array}{l}\text { First day adults, } \\
\text { daf-2(e1370) vs. } \\
\text { daf2(e1370); } \\
\text { daf-16( }(m 27) \text {. Pools } \\
\text { used, } 2 \text { biological } \\
\text { replicates, } 2 \\
\text { technical replicates } \\
\text { of each. }\end{array}$ & $\begin{array}{l}\text { cDNA } \\
(17871)\end{array}$ & 4 & \begin{tabular}{|c|} 
Arbitrary \\
cut-off of \\
1.5 fold in \\
all 4 arrays
\end{tabular} & 1646 & $\begin{array}{l}\text { sod-3, ins-30, heat } \\
\text { shock proteins, } \\
\text { proteases, "Mount } \\
15 \text { " }\end{array}$ \\
\hline $\begin{array}{l}\text { McElwee et } \\
\text { al., } 2004\end{array}$ & $\begin{array}{l}\text { First day adults, } \\
\text { daf-2(e1370) or } \\
\text { daf-2(m577) vs. } \\
\text { daf-2; daf-16. Pools } \\
\text { used, } 5 \text { biological } \\
\text { replicates per } \\
\text { genotype. }\end{array}$ & $\begin{array}{l}\text { Affymetrix } \\
\text { (“whole } \\
\text { genome") }\end{array}$ & 10 & $\begin{array}{l}\text { SAM, } \\
\text { EASE }\end{array}$ & 2274 & $\begin{array}{l}\text { Heat shock } \\
\text { proteins, } \\
\text { metabolism of } \\
\text { toxins, nutrient } \\
\text { uptake "Mount } \\
\text { 15" }\end{array}$ \\
\hline $\begin{array}{l}\text { Golden and } \\
\text { Melov, } 2004\end{array}$ & $\begin{array}{l}4 \text { adult ages, } 4-5 \\
\text { individuals per strain } \\
\text { per age, } \mathrm{N} 2 \text { and } \\
\text { daf-2(e1370). }\end{array}$ & cDNA (921) & 37 & \begin{tabular}{|c|} 
F test, linear \\
modeling, \\
empirical \\
Bayes \\
analysis \\
\end{tabular} & $\begin{array}{l}19 \text { (F stat) } 23 \text { (B } \\
\text { stat) N2, } 17 \text { (B } \\
\text { stat) daf-2 }\end{array}$ & $\begin{array}{l}\text { Heat shock } \\
\text { proteins, proteases }\end{array}$ \\
\hline $\begin{array}{l}\text { Viswanathan } \\
\text { et al., } 2005\end{array}$ & $\begin{array}{l}\text { Young adults, daf-16 } \\
\text { or N2, resveratrol- } \\
\text { treated worms vs. } \\
\text { untreated, pools } \\
\text { used, } 4 \text { biological } \\
\text { replicates per strain }\end{array}$ & $\begin{array}{l}\text { cDNA } \\
\text { ("genome } \\
\text { wide") }\end{array}$ & 8 & $\begin{array}{l}\text { Student t } \\
\text { test }\end{array}$ & $\begin{array}{c}3495 \text { daf-16, } \\
330 \mathrm{~N} 2\end{array}$ & $\begin{array}{l}\text { ER stress, } \\
\text { unfolded protein } \\
\text { response }\end{array}$ \\
\hline
\end{tabular}




\begin{tabular}{|c|c|c|c|c|c|c|}
\hline Study & $\begin{array}{l}\text { Experimental } \\
\text { Design }\end{array}$ & $\begin{array}{l}\text { Platform } \\
\text { (number of } \\
\text { genes) }\end{array}$ & \begin{tabular}{|c|}
$\begin{array}{c}\text { Number } \\
\text { of arrays }\end{array}$ \\
\end{tabular} & $\begin{array}{c}\text { Statistical } \\
\text { analysis }\end{array}$ & \begin{tabular}{|c|} 
Differentially \\
expressed genes
\end{tabular} & $\begin{array}{l}\text { Interesting genes } \\
\text { or gene families }\end{array}$ \\
\hline $\begin{array}{l}\text { Halaschek- } \\
\text { Wiener et al., } \\
2005\end{array}$ & $\begin{array}{l}\text { One population each } \\
\text { of } f e r-15(\mathrm{~b} 26 \mathrm{ts}) \text { at } \\
\text { days } 1 \text { and } 6 \text { of } \\
\text { adulthood, and of } \\
\text { fer- } 15(\mathrm{~b} 26 \mathrm{ts}) \text {; } \\
\text { daf- } 2(\mathrm{~m} 41) \text { at days } 1, \\
6 \text { and } 10 \text { of } \\
\text { adulthood }\end{array}$ & $\begin{array}{l}\text { SAGE } \\
(60000- \\
70000 \text { tags })\end{array}$ & 5 & $\begin{array}{l}\text { Discovery } \\
\text { Space } \\
\text { Platform }\end{array}$ & $\begin{array}{c}48 \text { age-related in } \\
\text { daf- } 2,265 \\
\text { age-matched } \\
\text { control vs } d a f-2, \\
130 \\
\text { physiologically } \\
\text { matched control } \\
\text { vs } d a f-2\end{array}$ & $\begin{array}{l}\text { Lipid, protein and } \\
\text { energy } \\
\text { metabolism, stress } \\
\text { response, cell } \\
\text { structure }\end{array}$ \\
\hline $\begin{array}{l}\text { Fisher and } \\
\text { Lithgow, } \\
2006\end{array}$ & $\begin{array}{l}4 \text { populations each } \\
\text { of sterile strains } \\
\text { containing } \\
\text { daf-12(rh61rh411) } \\
\text { or } d a f-12(r h 273), \\
\text { assayed vs mixed } \\
\text { stage N2 reference } \\
\text { RNA, with dye-flip } \\
\text { for each sample }\end{array}$ & $\begin{array}{l}\text { Oligo (22490 } \\
\text { features) }\end{array}$ & 16 & SAM & 225 (SAM) & $\begin{array}{l}\text { Sperm-related, } \\
\text { digestion, } \\
\text { detoxifcation, } \\
\text { DUF141 } \\
\text { domain-containing }\end{array}$ \\
\hline
\end{tabular}

The first microarray study that looked for gene expression changes associated with age in C. elegans examined eight ages from oocyte to adult (Hill et al., 2000), including two adult time points (60 hours and 14 days). A single array per age was carried out on RNA extracted from thousands of synchronized worms. This study used Affymetrix arrays containing 18791 predicted open reading frames (ORFs). First, genes were filtered to identify those that were detected as expressed at at least one age. Then ANOVA $(p<0.001)$ was applied to identify genes whose expression changed during the life cycle. Pertinent to aging, several classes of genes were noted to decline in expression between the 60-hour and 2-week time points, including muscle-related genes and metabolic genes, suggesting a decline in muscle function, metabolic activity and the synthesis of extracellular matrix. These results are especially interesting in light of the report that muscle deterioration is a hallmark of nematode aging (Herndon et al., 2002).

The first study examining longitudinal aging in nematodes (Lund et al., 2002) used cDNA arrays containing 17871 genes, examined six age categories, and used three different sterile strains. The data were analyzed via ANOVA ( $\mathrm{p}<0.001)$, resulting in a list of 201 genes with age-related expression changes. After the exclusion of 34 genes whose expression remained constant after four days of age, and three genes for which variance due to strain exceeded that due to age, only 164 genes, less than $1 \%$ of the genome, were found to change expression with age. This modest result may indicate that some age-related expression changes were too small to detect. This may also reflect a lack of coordinated gene expression with aging, as might be predicted by evolutionary theory, and consistent with proteomic studies of aging which found relatively few proteins changing in abundance with age (Johnson and McCaffrey, 1985).

At the time of publication, 72 of the genes identified by this study had been annotated, including sir-2.1, two heat shock proteins (hsp), three Tc3 transposons, and an insulin homologue ins-2. Examination of gene families related to these genes identified additional genes that changed expression with age but which had not passed the criteria for significance in the ANOVA analysis, including insulin homologues such as ins-7, several heat shock genes that shared a common expression profile of a peak in expression at mid life and subsequent decline at old age, and a general increase in expression of all mobile genetic elements. The increase in transposon expression is interesting because it implicates genomic instability as a potential mechanism of aging in C. elegans. To test whether mitochondrial dysfunction or reactive oxidative species were implicated in C. elegans aging, the authors also examined mitochondria-associated genes and genes involved in response to oxidative stress, but no consistent expression changes were seen. Finally, the genes which were differentially expressed with age were found to be over-represented in a group of genes called Mount 15 (Kim et al., 2001). Genes in Mount 15 were found to increase expression with age; interestingly, most of the genes in Mount 15 were also found to be upregulated in dauers in an additional microarray experiment. 
A second study of longitudinal wild-type aging used cDNA arrays containing only 921 genes, chosen with an emphasis on stress-response pathways (Golden and Melov, 2004). This study looked at wild-type N2, as well as a long-lived daf-2 strain, at four ages. These authors chose to assay expression in individual nematodes as a proof of principle of an approach that could facilitate the testing of certain theories of aging (see below). Data analysis involved an $\mathrm{F}$ test to find genes that differentiated the two genotypes, and linear modeling and empirical Bayes analysis to find genes differentially expressed in pairwise comparisons of each age vs. four-day-old worms. Though the study is limited in terms of the number of genes examined and the number of individuals used (4 per time point), several conclusions were reached. First, even at older ages, individual worms resembled each other with respect to gene expression, arguing against a global dysregulation of gene expression as a cause of aging. Clustering revealed two groups of genes that changed in a coordinated manner with age. The first cluster contained heat shock proteins, which peaked in expression at 14 days then declined, similar to the pattern identified in the study of Lund et al. (Lund et al., 2002). However, this pattern was found to be identical in chronologically matched $\mathrm{N} 2$ and daf-2, indicating that in the absence of external stress, heat shock protein expression is unlikely to explain the longevity of the daf-2 strain. The second cluster contained proteases that decrease in expression with age in N2 but not in daf-2, suggesting that maintenance of these proteases may contribute to daf-2 longevity. It is interesting in this regard that RNAi of an aspartyl protease was found to decrease daf-2 lifespan, but have only a small effect on N2 lifespan (McElwee et al., 2003). The five genes that best differentiated the two genotypes were thaumatin, a complex III subunit, a proteasome component, actin, and akt2. These genes highlight five prevalent areas associated with aging research: pathogen defense, bioenergetics, protein turnover, muscle maintenance, and cell survival.

\subsection{Studies involving dauer formation gene mutants}

Because mutations in components of the insulin-like signaling pathway can extend lifespan in C. elegans, the majority of microarray studies have sought to gain insight into aging either by identifying differences in gene expression between wild-type and long-lived daf-2 mutant worms (Golden and Melov, 2004; Halaschek-Wiener et al., 2005), or between $d a f-2$ and daf-2; daf-16 double mutants (McElwee et al., 2003; McElwee et al., 2004; Murphy et al., 2003). As daf-16 is required for longevity in daf-2 mutants, it is expected that genes regulated by the daf-16 transcription factor play a role in the longevity of the daf-2 strain. A direct biochemical approach has also been applied to identify genes that are direct targets of DAF-16 (Oh et al., 2006). An additional study (Fisher and Lithgow, 2006) has compared gene expression in two strains containing mutations of another gene related to dauer formation, daf-12, that can also have an effect on adult life span.

Murphy et al. (Murphy et al., 2003) aimed to identify targets of daf-16, a transcription factor required for long life in many AGE mutants. This study involved two sets of experiments, each using full-genome cDNA microarrays. In the first approach, fourteen arrays were used to examine gene expression in long-lived mutant strains on the first day of adulthood. One of these arrays compared gene expression between daf-2(mu150) and wild type worms, one compared daf-2(e1370) to the double mutant daf-2(e1370);daf-16(mu86), and others compared strains carrying age-1, daf-2(mu150) or daf-2(e1368) on a mutant background (fer-15;fem-1) to their appropriate control strain. Through these multiple comparisons, the authors were able to look for genes whose expression changed in the same way in multiple long-lived models in several backgrounds, and whose expression changes were reversed by the presence of the daf-16 mutation. Significance analysis of microarrays (SAM; Tusher et al., 2001) was used to identify genes that changed similarly in all comparisons. Additionally, genes with at least fourfold expression changes were clustered via hierarchical clustering.

These results were then compared to an additional set of arrays involving two time courses, comparing gene expression in sterile worms raised on control bacteria, daf-2 RNAi, or both daf-2 and daf-16 RNAi at ten different times between 0 and 2 days of adulthood, or at 10 times from 0 to 8 days of adulthood. All the data were combined, and hierarchical clustering used to identify genes whose expression changed in similar ways across the experiment. Because of the interest in identifying targets of daf-16, clusters of genes whose expression was reversed by the daf-16 RNAi were of interest. Two groups of genes, 263 class 1 genes, and 251 class 2 genes, were identified. Fifty-three genes were selected from these classes, and their expression reduced by RNAi; in approximately $75 \%$ of cases, the RNAi resulted in the predicted change in life span. Included in the lists of genes that are associated with changes in life span were metabolic genes, stress response genes, and several proteases.

Similar results were identified in a much smaller study comparing gene expression profiles between $d a f-2$ and daf-2; daf-16 strains (McElwee et al., 2003). This study involved four cDNA arrays. A list is provided of 1646 genes whose expression differed by at least 1.5-fold in all four experiments, but no statistical analysis is reported. The list of genes with higher expression in daf-2 overlapped with the same cluster of genes (Mountain 15; Kim et al., 2001), discussed in the study of wild-type $C$. elegans aging by Lund et al. (see above). The expression of several gene 
families relevant to theories of aging were plotted to look for a trend towards differential expression between $d a f-2$ and $d a f-2$; daf-16. Metabolism-related genes were found to have lower expression in daf-2. This study also carried out RNAi of genes of interest, and found that reducing ins-30 (zc443.2, discussed in the paper as ins-7, see erratum to McElwee 2003) or superoxide dismutase expression resulted in an unexpected extension of life span. RNAi of a protease, ZK384.3, reduced daf-2 lifespan but had no effect on N2 life span, consistent with the hypothesis that maintenance of protease expression plays a role in extended life span of $d a f-2$.

McElwee et al. followed up with a larger study (McElwee et al., 2004) comparing gene expression between daf-2 and daf-2;daf-16 nematodes, and further investigated the inference of their earlier work that a dauer-like transcriptional profile is found in daf-2 mutants. This study used oligo arrays, rather than cDNA arrays as in the other studies. Two different daf-2 alleles were examined on the first day of adulthood in the presence and absence of a daf-16 mutation. Five biological replicates were conducted per strain, and all ten experiments were combined and SAM was used to identify a list of 2274 differentially expressed genes, Additionally, EASE was used to identify classes of genes based on gene ontology that were differentially expressed. The authors also re-analyzed the results of a cDNA array study of gene expression changes upon dauer recovery (Wang and Kim, 2003) and compared these results with their gene list; $16 \%$ of the genes that changed in expression during dauer recovery changed similarly in $d a f-2 ; d a f-16$ vs daf-2, and many of the same gene ontology classes were over-represented in both gene sets. This common dauer and $d a f-2$ transcriptional profile included gene classes related to the metabolism and excretion of toxic metabolites, leading to the hypothesis that such toxins may cause damage that contributes to aging. Their results are interpreted as being in agreement with the disposable soma theory of aging. The authors also compared their results with the two earlier studies mentioned above (McElwee et al., 2003; Murphy et al., 2003), finding 90 common genes.

One microarray study has compared gene expression between daf-2(e1370) and N2 over the N2 lifespan (Golden and Melov, 2004). As mentioned earlier, this study considered only a limited number of genes (921), and unfortunately did not examine $d a f-2$ at later points in the daf-2 lifespan (the ages examined were four, nine, 14 and 19 days of age at $20^{\circ} \mathrm{C}$ ). Hence, though it is interesting to note that expression of several protease genes declined with age in N2 but was maintained in daf-2 at the same ages (discussed above), this study was not able to determine whether expression of these genes did fall later over the course of the daf-2 life span.

Halaschek-Wiener et al. (Halaschek-Wiener et al., 2005) used SAGE to compare gene expression profiles between chronologically-matched and physiologically-matched daf-2(m4l) and control animals. As in the study of Lund et al., the strains carried a temperature-sensitive fertility mutation to prevent contamination of the cultures by progeny, and to avoid collecting transcripts from developing embryos within the mothers. SAGE has an advantage over traditional microarray technology in that it does not require prior knowledge of the identity of expressed sequences as is necessary to synthesize the probes placed on the chip in traditional microarrays. In this work, daf- 2 animals were assayed at one, six, and ten days of age and control animals at one and six days of age $\left(25.5^{\circ} \mathrm{C}\right)$, ten and six days being the latest points before animals began to die in the daf-2 and control populations respectively. The authors examined the daf-2 SAGE tags for those that progressively increased or decreased with age. Several heat shock and stress response tags increased dramatically with age in $d a f-2$, while remaining relatively low in one and six-day-old control nematodes. Genes associated with sperm function and encoding collagens decreased with age in $d a f-2$. The authors then compared six-day-old $d a f-2$ with six-day-old control animals (chronologically matched populations) and ten-day-old $d a f-2$ with six-day-old controls (physiologically matched populations). In the chronologically-matched populations, small heat shock proteins and transthyretin-like genes were more highly expressed in daf-2 than controls, while many metabolic pathways, including lipid, nucleic acid, and protein metabolism, were expressed at lower levels in daf-2, implying that the long-lived strain is hypometabolic compared to controls. This is consistent with biochemical studies of long-lived C. elegans strains (Van Voorhies and Ward, 1999). The difference in expression of metabolic genes disappeared when the animals were physiologically matched. The authors compared their results with those of Murphy et al. and McElwee et al., and found common themes including stress response, lipid metabolism, and protein metabolism.

Fisher and Lithgow (Fisher and Lithgow, 2006) observed overlap in repressed genes between their study of a long-lived strain containing a mutation in daf-12, and those identified in the studies of daf-2 and daf-16. These authors examined gene expression in two strains containing different mutations of $d a f-12$, one strain short-lived and one long-lived. Four independent populations of each mutant were assayed on full-genome oligo arrays, using mixed-stage wild type worms as a control. Each array was repeated as a dye-flip experiment, resulting in a total of 16 arrays that were analyzed via SAM. Up-regulated genes in the long-lived strain were enriched in sperm-related processes, while down-regulated genes were enriched in processes related to metabolism. Comparison of the $d a f-12$ related gene lists with the dauer and $d a f-2$ gene expression profiles revealed an overlapping set of repressed genes 
enriched in genes containing a DUF141 domain (Domain of unknown function), several of which have been confirmed to limit life span via RNAi. Bioinformatic analysis lead the authors to propose that these related proteins may represent a novel family of peptide hormones, secreted in response to daf-2 and daf-12 signaling.

\subsection{Studies of life-extension paradigms}

One study has used microarray analysis of gene expression to investigate a pharmacologic life-extension paradigm (Viswanathan et al., 2005). This study examined gene expression changes in resveratrol-treated $C$. elegans. Both wild type and daf-16 mutant worms were treated with resveratrol, and four biological replicates were carried out per strain. The $\log$ of the differential expression was averaged for the four arrays, and a student $t$ test applied to identify differentially expressed genes (Jiang et al., 2001). Interestingly, ten times more genes were identified in the daf-16 mutant background (3495) than in N2 (330). Focusing on genes common to both backgrounds identified a class of ER stress response genes comprised of prion-like Q/N proteins (PQN) and activated in blocked unfolded protein response (ABU) proteins, which may function in an ER pathway in parallel with the canonical unfolded protein response. RNAi of two of these genes abolished the effect of resveratrol on life span.

\section{What have we learned?}

\subsection{Conclusions drawn from studies of worm aging}

The studies of gene expression changes associated with wild-type worm aging point to interesting age-related phenomena, but leave open many questions about worm aging. The study of Hill et al. (Hill et al., 2000) implicated age-related muscle deterioration and a decline in metabolic function. Muscle deterioration has been described at the microscopic level in C. elegans aging (Herndon et al., 2002), but the decline in expression of metabolic genes was not observed by the longitudinal study of Lund et al. (Lund et al., 2002). Lund et al. found relatively few genes to change significantly with age, which is interpreted as support for the theory that the accumulation of molecular and cellular damage with time is a basis for aging. The increase in expression of transposable elements in the study of Lund et al. also points to a potential role of genomic instability, while an age-related increase in the expression of genes that are highly expressed in dauers suggests that a common survival mechanism is activated in dauer larvae and older nematodes. Golden and Melov observed the same mid-life peak in small heat-shock protein (hsp) expression described by Lund et al. (Lund et al., 2002). Lund et al. hypothesized that the late-life decline in hsp expression might contribute to senescence, but in the work of Golden and Melov (2004), hsp expression was found to be identical in age-matched $d a f-2$ and wild type nematodes. It is interesting that Halaschek-Wiener (Halaschek-Wiener et al., 2005), via SAGE, detected the same increase in small hsp expression in daf-2 nematodes between one and ten days of age, but a decline in expression of these genes between one and six days in wild type nematodes. It has been reported that though SAGE and microarray technologies are frequently in good accord with respect to highly expressed genes, overall agreement is only modest (van Ruissen et al., 2005), and poor agreement has been described for dauer expression profiling by the two approaches (Wang and Kim, 2003). The contradictions between the microarray and SAGE data related to N2 and daf-2 aging deserve further investigation.

\subsection{Conclusions drawn from the study of dauer formation mutants}

Interestingly, most studies have focused on differences in gene expression between daf-2 and daf-2;daf-16 rather than between $\mathrm{N} 2$ and $d a f-2$. Presumably, this is because mutation of $d a f-16$ shortens (normalizes) daf-2 life span, and so expression differences between daf-16 (+) and daf-16 (-) in the daf-2 background are expected to be involved in daf-2 longevity. However, no studies have yet been published directly comparing daf-16 to wild type nematodes. Mutation of daf-16 also shortens N2 life span, and examining daf-16 mutant worms directly would be an important means to identify daf-16 targets, and would aid in the interpretation of the daf-2;daf-16 gene expression profiles.

Complementary techniques will also be important to understanding the results of gene expression profiling in these models. Microarray and SAGE analysis can identify genes whose expression changes in response to conditions expected to change the binding of DAF-16 to promoters, but cannot differentiate between direct and indirect targets of the transcription factor. Genome-wide biochemical analyses such as chromatin immunoprecipitation (ChIP) can identify direct targets whose promoters are bound by the transcription factor. Oh et al. (Oh et al., 2006) applied ChIP to identify DAF-16 targets, finding 130 genes that were immunoprecipitated with an anti-DAF-16 antibody in the strain daf-2(e1370). These genes are involved in processes such as metabolism, development, and detoxification and stress response, but intriguingly, $36 \%$ are of unknown function. Interestingly, only 88 of these had a consensus 
DAF-16 binding site in the promoter, while 15 had a predicted DAF-16 site in the coding region, and 27 had no known DAF-16 binding site at all. Further analysis of the first 33 genes containing a predicted DAF-16 consensus binding site found that in 10 of these genes, DAF-16 was not binding to the canonical site but to a previously unknown binding site. These results indicate that bioinformatics approaches are not sufficient to understanding the complexities of the regulation of gene expression.

Perhaps not surprisingly, since $d a f-16$ is required for both dauer formation and daf-2 longevity, the gene sets identified by comparing $d a f-2$ with $d a f-2$;daf-16 overlaps substantially with the gene sets identified by comparing dauer with non-dauer larvae. Less expected is the observation that a dauer-like transcriptional profile may be activated in normal worms with age (Lund et al., 2002), pointing to the significance of determining what, in the dauer transcriptional profile, constitutes an enhanced survival mechanism. Dauer animals have increased stress-resistance, and gene expression profiling confirms that several stress-response genes are upregulated in $d a f-2$ animals relative to daf-2;daf-16 double mutants. Dauers also have an altered metabolism, consistent with the requirement that they survive in the absence of food. It is interesting, therefore, that gene expression profiling implies that both long-lived $d a f-2$ and $d a f-12$ worms are hypometabolic, consistent with biochemical studies of metabolic rate in long-lived strains (Van Voorhies and Ward, 1999).

Proteases were identified as age-related genes in each of the studies summarized here. Additionally, ER stress was implicated in the pharmacologic life extension model, which also points to a role for improved protein folding, or a decrease in the amount of mis-folded proteins, in enhancing life span. Consistent with this, reducing expression of relevant genes via RNAi reduced $d a f-2$ or resveratrol-treated life span. However any experiment resulting in a shortened life span must be interpreted with the caveat that a shortened life span could result from the worms being sick, rather than aging more quickly. Overall, these studies implicate an accumulation of damaged or misfolded proteins as playing a role in limiting wild-type C. elegans life span.

\section{Future directions}

Much has been learned from the expression profiling that has been done related to C. elegans aging. Yet, many questions remain. Detailed longitudinal studies of gene expression over the life span of $d a f-2$ or other long-lived mutants would aid in the interpretation of the expression changes reported for wild type nematodes, as this would allow the determination of whether age-related changes also occur in the long-lived strains, or perhaps occur on a delayed time scale.

Recent studies indicate that there is a substantial stochastic element to nematode aging (Herndon et al., 2002; Lund et al., 2002), which may preclude the identification of age-related expression changes when pools of worms are studied. The assay of gene expression in individual nematodes may allow the detection of an increase in variance in gene expression with age, as might be predicted if aging is accompanied by a loss of tight regulation of expression. Also, the study of individuals may allow the identification of sub-sets of worm aging, whose associated expression profiles might be averaged out by the study of pools.

Microarray studies can and have pointed to pathways and systems deserving of further examination relative to worm aging. As more reports of expression profiling of worm aging accumulate, using various strains and platforms, a better understanding of the universality of specific changes can be gained. Some studies have already begun to look for similarities of age-related expression patterns across species (McCarroll et al., 2004). However, in carrying out such comparative studies, one has to be aware of the possibility of pseudo-replication, which introduces significant error (see Melov and Hubbard (2004), for discussion of pseudo-replication in the context of microarrays).

Interpretation of expression profiles associated with aging is complicated by the fact that in some cases the observed expression changes may be causal and reflect processes that contribute to the aging phenotype, or may be a result of or reaction to age-related phenomena. Experiments such as reduction of expression through RNAi can and have been used to support the involvement of a specific gene in limiting life span, but will not provide insight if the gene must change expression in conjunction with other genes to exert an effect. The power of gene expression profiling techniques is the ability to identify suites of genes or gene families involved in a complex process such as aging. Further studies will be necessary to differentiate between cause and effect. 


\section{References}

Bahar, R., Hartmann, C.H., Rodriguez, K.A., Denny, A.D., Busuttil, R.A., Dolle, M.E., Calder, R.B., Chisholm, G.B., Pollock, B.H., Klein, C.A., and Vijg, J. (2006). Increased cell-to-cell variation in gene expression in ageing mouse heart. Nature 441, 1011-1014. Abstract Article

Barnes, M., Freudenberg, J., Thompson, S., Aronow, B., and Pavlidis, P. (2005). Experimental comparison and cross-validation of the Affymetrix and Illumina gene expression analysis platforms. Nucleic Acids Res. 33, 5914-5923. Abstract Article

Beckman, K.B., and Ames, B.N. (1998). The free radical theory of aging matures. Physiol. Rev. 78, 547-581. Abstract

Bowtell, D., and Sambrook, J., eds. (2003). DNA Microarrays (Cold Spring Harbor, New York: Cold Spring Harbor Laboratory Press).

Fabian, T.J., and Johnson, T.E. (1995). Identification genes that are differentially expressed during aging in Caenorhabditis elegans. J. Gerontol. A Biol. Sci. Med. Sci. 50, B245-B253. Abstract

Fabian, T.J., and Johnson, T.E. (1995). Total RNA, rRNA and poly(A)+RNA abundances during aging in Caenorhabditis elegans. Mech. Ageing Dev. 83, 155-170. Abstract Article

Finch, C.E. (1990). Longevity, Senescence, and the Genome, Paperback edition edn (Chicago: The University of Chicago Press).

Fisher, A.L., and Lithgow, G.J. (2006). The nuclear hormone receptor DAF-12 has opposing effects on Caenorhabditis elegans lifespan and regulates genes repressed in multiple long-lived worms. Aging Cell 5, 127-138. Abstract Article

Friedman, D.B., and Johnson, T.E. (1988). A mutation in the age-1 gene in Caenorhabditis elegans lengthens life and reduces hermaphrodite fertility. Genetics 118, 75-86. Abstract

Golden, T.R., and Melov, S. (2004). Microarray analysis of gene expression with age in individual nematodes. Aging Cell 3, 111-124. Abstract Article

Halaschek-Wiener, J., Khattra, J.S., McKay, S., Pouzyrev, A., Stott, J.M., Yang, G.S., Holt, R.A., Jones, S.J., Marra, M.A., Brooks-Wilson, A.R., and Riddle, D.L. (2005). Analysis of long-lived C. elegans daf-2 mutants using serial analysis of gene expression. Genome Res. 15, 603-615. Abstract Article

Herndon, L.A., Schmeissner, P.J., Dudaronek, J.M., Brown, P.A., Listner, K.M., Sakano, Y., Paupard, M.C., Hall, D.H., and Driscoll, M. (2002). Stochastic and genetic factors influence tissue-specific decline in ageing C. elegans. Nature 419, 808-814. Abstract Article

Hill, A.A., Hunter, C.P., Tsung, B.T., Tucker-Kellogg, G., and Brown, E. L. (2000). Genomic analysis of gene expression in C. elegans. Science 290, 809-812. Abstract Article

Jiang, M., Ryu, J., Kiraly, M., Duke, K., Reinke, V., and Kim, S.K. (2001). Genome-wide analysis of developmental and sex-regulated gene expression profiles in Caenorhabditis elegans. Proc. Natl. Acad. Sci. U.S.A. 98, $218-223$. Abstract Article

Johnson, T.E. (2002). Subfield history: Caenorhabditis elegans as a system for analysis of the genetics of aging. Sci. Aging Knowledge Environ., 1-9. Abstract Article

Johnson, T.E., and McCaffrey, G. (1985). Programmed aging or error catastrophe? An examination by two-dimensional polyacrylamide gel electrophoresis. Mech. Ageing Dev. 30, 285-297. Abstract Article

Kenyon, C., Chang, J., Gensch, E., Rudner, A., and Tabtiang, R. (1993). A C. elegans mutant that lives twice as long as wild type. Nature 366, 461-464. Abstract Article 
Kim, S.K., Lund, J., Kiraly, M., Duke, K., Jiang, M., Stuart, J.M., Eizinger, A., Wylie, B.N., and Davidson, G.S. (2001). A gene expression map for Caenorhabditis elegans. Science 293, 2087-2092. Abstract Article

Kimura, K.D., Tissenbaum, H.A., Liu, Y., and Ruvkun, G. (1997). daf-2, an insulin receptor-like gene that regulates longevity and diapause in Caenorhabditis elegans [see comments]. Science 277, 942-946. Abstract Article

Kirkwood, T.B. (1977). Evolution of ageing. Nature 270, 301-304. Abstract Article

Kirkwood, T.B., and Holliday, R. (1979). The evolution of ageing and longevity. Proc. R. Soc. Lond., B, Biol. Sci. 205, 531-546. Abstract

Lin, K., Hsin, H., Libina, N., and Kenyon, C. (2001). Regulation of the Caenorhabditis elegans longevity protein DAF-16 by insulin/IGF-1 and germline signaling. Nat. Genet. 28, 139-145. Abstract Article

Lund, J., Tedesco, P., Duke, K., Wang, J., Kim, S., and Johnson, T. (2002). Transcriptional Profile of Aging in $C$. elegans. Curr. Biol. 12, 1566. Abstract Article

McCarroll, S.A., Murphy, C.T., Zou, S., Pletcher, S.D., Chin, C.S., Jan, Y.N., Kenyon, C., Bargmann, C.I., and Li, H. (2004). Comparing genomic expression patterns across species identifies shared transcriptional profile in aging. Nat. Genet. 36, 197-204. Abstract Article

McElwee, J., Bubb, K., and Thomas, J.H. (2003). Transcriptional outputs of the Caenorhabditis elegans forkhead protein DAF-16. Aging Cell 2, 111-121. Erratum in: Aging Cell (2003) 2(6), 341. Abstract Article

McElwee, J.J., Schuster, E., Blanc, E., Thomas, J.H., and Gems, D. (2004). Shared transcriptional signature in Caenorhabditis elegans Dauer larvae and long-lived daf-2 mutants implicates detoxification system in longevity assurance. J. Biol. Chem. 279, 44533-44543. Abstract Article

Melov, S., and Hubbard, A. (2004). Microarrays as a tool to investigate the biology of aging: a retrospective and a look to the future. Sci. Aging Knowledge Environ. 2004, re7. Abstract Article

Murphy, C.T., McCarroll, S.A., Bargmann, C.I., Fraser, A., Kamath, R.S., Ahringer, J., Li, H., and Kenyon, C. (2003). Genes that act downstream of DAF-16 to influence the lifespan of Caenorhabditis elegans. Nature 424, 277-283. Abstract Article

Ogg, S., Paradis, S., Gottlieb, S., Patterson, G.I., Lee, L., Tissenbaum, H.A., and Ruvkun, G. (1997). The Fork head transcription factor DAF-16 transduces insulin-like metabolic and longevity signals in C. elegans. Nature 389, 994-999. Abstract Article

Oh, S.W., Mukhopadhyay, A., Dixit, B.L., Raha, T., Green, M.R., and Tissenbaum, H.A. (2006). Identification of direct DAF-16 targets controlling longevity, metabolism and diapause by chromatin immunoprecipitation. Nat. Genet. 38, 251-257. Abstract Article

Riddle, D.L., Swanson, M.M., and Albert, P.S. (1981). Interacting genes in nematode dauer larva formation. Nature 290, 668-671. Abstract Article

Somel, M., Khaitovich, P., Bahn, S., Paabo, S., and Lachmann, M. (2006). Gene expression becomes heterogeneous with age. Curr. Biol. 16, R359-360. Abstract Article

Tusher, V.G., Tibshirani, R., and Chu, G. (2001). Significance analysis of microarrays applied to the ionizing radiation response. Proc. Natl. Acad. Sci. U.S.A. 98, 5116-5121. Abstract Article

van Ruissen, F., Ruijter, J.M., Schaaf, G.J., Asgharnegad, L., Zwijnenburg, D.A., Kool, M., and Baas, F. (2005). Evaluation of the similarity of gene expression data estimated with SAGE and Affymetrix GeneChips. BMC Genomics 6, 91. Abstract Article

Van Voorhies, W.A., and Ward, S. (1999). Genetic and environmental conditions that increase longevity in Caenorhabditis elegans decrease metabolic rate. Proc. Natl. Acad. Sci. USA. 96, 11399-11403. Abstract Article 
Velculescu, V.E., Zhang, L., Vogelstein, B., and Kinzler, K.W. (1995). Serial analysis of gene expression. Science 270, 484-487. Abstract Article

Viswanathan, M., Kim, S.K., Berdichevsky, A., and Guarente, L. (2005). A role for SIR-2.1 regulation of ER stress response genes in determining C. elegans life span. Dev. Cell 9, 605-615. Abstract Article

Walker, D.W., McColl, G., Jenkins, N.L., Harris, J., and Lithgow, G. J. (2000). Evolution of lifespan in C. elegans. Nature 405, 296-297. Abstract Article

Wang, J., and Kim, S.K. (2003). Global analysis of dauer gene expression in Caenorhabditis elegans. Development 130, 1621-1634. Abstract Article

Williams, G.C. (1957). Pleiotropy, natural selection and the evolution of senescence. Evolution 11, 398-411. Article

Yang, Y.H., and Speed, T. (2002). Design issues for cDNA microarray experiments. Nat. Rev. Genet. 3, 579-588. Abstract Article

All WormBook content, except where otherwise noted, is licensed under a Creative Commons Attribution License. 